\title{
Common Marmoset (Callithrix jacchus) as a Primate Model for Behavioral Neuroscience Studies
}

Noeline W Prins ${ }^{a}$, Eric Pohlmeyer ${ }^{a}$, Shubham Debnath ${ }^{a}$, Ramanamurthy Mylavarapu ${ }^{a}$, Shijia Geng ${ }^{a}$, Justin C Sanchez ${ }^{a}$, Daniel Rothen ${ }^{\mathrm{b}}$, and Abhishek Prasad ${ }^{\mathrm{a}}$

${ }^{a}$ Department of Biomedical Engineering, University of Miami, Coral Gables, FL 33146

${ }^{b}$ Division of Veterinary Resources, University of Miami, Coral Gables, FL 33146

Author Current Affliliations:

Eric Pohlmeyer: John Hopkins University Applied Physics Laboratory, Laurel, MD 20723

Shijia Geng: The Center for Computational Science, University of Miami, Coral Gables, FL 33146

Justin C Sanchez: Defense Advanced Research Projects Agency, Arlington, VA 22203

Corresponding author: Abhishek Prasad, Ph.D.

1251 Memorial Drive, MEA 219A,

Coral Gables, 33146 FL.

a.prasad@miami.edu

Number of pages: 39

Number of figures: 8

Number of Tables: 2

Abstract (250 max): 242

\section{Acknowledgements:}

This work was supported by DARPA REPAIR N66001-10-C-2008, DoD W81XWH-15-0332, and NIH 1DP2EB022357-01. The authors would like to thank Dr. Kathleen Burman (Monash University) for helpful advice on the location of arm and hand motor cortex in marmosets. The authors would like to thank the University of Miami, Division of Veterinary Resources (DVR) for the animal care support. 


\section{Common Marmoset (Callithrix jacchus) as a Primate Model for}

\section{Behavioral Neuroscience Studies}

3 Noeline W Prins ${ }^{a}$, Eric Pohlmeyer ${ }^{a}$, Shubham Debnath $^{a}$, Ramanamurthy Mylavarapu $^{\mathrm{a}}$,

$4 \quad$ Shijia Geng ${ }^{a}$, Justin C Sanchez ${ }^{a}$, Daniel Rothen ${ }^{b}$ and Abhishek Prasad ${ }^{a}$

$5 \quad{ }^{a}$ Department of Biomedical Engineering, University of Miami, Coral Gables, FL 33146

$6 \quad$ bivision of Veterinary Resources, University of Miami, Coral Gables, FL 33146

7 Author Current Affliliations:

8 Eric Pohlmeyer: John Hopkins University Applied Physics Laboratory, Laurel, MD 20723

9 Shijia Geng: The Center for Computational Science, University of Miami, Coral Gables, FL 33146

10 Justin C Sanchez: Defense Advanced Research Projects Agency, Arlington, VA 22203

\section{Abstract (250 word limit)}

Background: The common marmoset (Callithrix jacchus) has been proposed as a suitable bridge between rodents and larger primates. They have been used in several types of research including auditory, vocal, visual, pharmacological and genetics studies. However, marmosets have not been used as much for behavioral studies.

New Method: Here we present data from training 12 adult marmosets for behavioral neuroscience studies. We discuss the husbandry, food preferences, handling, acclimation to laboratory environments and neurosurgical techniques. In this paper, we also present a custom built "scoop" and a monkey chair suitable for training of these animals.

Results: The animals were trained for three tasks: 4 target center-out reaching task, reaching tasks that involved following robot actions, and touch screen task. All animals learned the center-out reaching task within 1-2 weeks whereas learning reaching tasks following robot 
actions task took several months of behavioral training where the monkeys learned to associate robot actions with food rewards.

Comparison to Existing Method: We propose the marmoset as a novel model for behavioral neuroscience research as an alternate for larger primate models. This is due to the ease of handling, quick reproduction, available neuroanatomy, sensorimotor system similar to larger primates and humans, and a lissencephalic brain that can enable implantation of microelectrode arrays relatively easier at various cortical locations compared to larger primates.

Conclusion: All animals were able to learn behavioral tasks well and we present the marmosets as an alternate model for simple behavioral neuroscience tasks.

Keywords: marmoset (Callithrix jacchus), nonhuman primate (NHP), behavioral neuroscience, small NHP model

\section{Introduction}

Common marmosets (Callithrix jacchus) are New World primates originating from South and Central America. In recent years, the use of common marmosets in research studies have grown due to their small size, ease of handling, ability to breed in captivity and do not present the same zoonotic risks as other non-human primates (NHP) (Tokuno et al., 2015). Marmosets are small (typical body weight 250-600g, adult body weight approximately 400g) (Hearn, 1983), arboreal, diurnal, and live in family groups in the wild. They are highly visual and olfactory animals and feed on gum, small insects, and are frugivores (fruit eaters). In comparison to macaques (currently the most used NHP model), marmosets are easier to breed in captivity and maintain in small groups. This is in part due to their small size, shorter gestation times and earlier sexual maturation (Hearn, 1983). One can also avoid the routine hazards of working with larger NHPs. In addition, the marmosets are not threatened or 
endangered in the wild (Abbott et al., 2003). Marmosets due to their key advantages have been replacing rodents in neuroscience research as the rodent brain does not always map to higher order mammals (Cyranoski, 2009). The brain structure of marmosets, including cortical organization, shares many similarities to that of humans and larger primate models and marmoset use in neuroscience research has continually grown (Figure 1). Additionally, their cortical structure is lissencephalic, which can simplify obtaining electrophysiological recordings from many different regions (Tokuno et al., 2015; Walker et al., 2016).

The common marmoset has also been regularly used for auditory studies. Their rich vocal behavior displayed both in wild and captivity has been studied to understand evolutionary vocal communication (Kajikawa et al., 2008; Simões et al., 2010; Choi et al., 2015; Eliades and Miller, 2016; Miller et al., 2016). They are used in visual studies for directional preference maps and several studies have compared them to larger monkey models (Troilo et al., 1993; Elston and Jelinek, 2001; Roe et al., 2005). They are used as models of spinal cord injury (Fouad et al., 2004; Iwanami et al., 2005; Schorscher-Petcu et al., 2009; Kobayashi et al., 2012; Bowes et al., 2013; Kondo et al., 2015) and have been replacing larger monkeys in Parkinson research as a smaller MPTP (1-methyl-4-phenyl-1,2,3,6tetrahydropyridine) model (Nash et al., 2000; Van Vliet et al., 2006; Van Vlieta et al., 2008; Philippens et al., 2010; Santana et al., 2014). New interests have been made in using marmosets as a model for aging and age-related diseases (Tardif et al., 2011). Their use in pharmacological, pathogen and immune studies have also been growing (Smith et al., 2001; Jagessar et al., 2010; Kap et al., 2010; Carrion and Patterson, 2012; Jagessar et al., 2013). The successful creation of transgenic marmosets provides an opportunity to study various human diseases in a primate model compared to rodent models (Antunes et al., 1998; Sasaki et al., 2009; Bert et al., 2012). The relatively high reproduction rate of marmosets compared toother primates make them potentially suitable for transgenic modification. They have been the animal model of choice for the Brain Project in Japan (Cyranoski, 2014; Kishi et al., 
2014; Okano and Mitra, 2015; Okano et al., 2015) and the Marmoset Genome Project (Sasaki et al., 2009; Harris et al., 2014; Sequencing, 2014).

However, common marmosets have not been used as much for behavioral studies to the best of our knowledge. We have previously reported findings of reward and orientation information from the striatum in marmosets (Prins et al., 2013a; Prins et al., 2013b) and reported marmosets in brain-machine interface (BMI) tasks (Pohlmeyer et al., 2014; Prins et al., 2014). In this paper, we present our experience and findings from working with 12 successfully trained marmosets for behavioral tasks. Through this, we seek to establish a training paradigm that can help other laboratories interested in using a smaller NHP model in behavioral studies.

\section{Methods}

In this work, we report observations based upon our experience working with 12 adult male marmosets. We trained the animals to perform a variety of behavioral tasks as part of BMI studies. All animal care, surgical, and research procedures were performed in accordance with the National Research Council Guide for the Care and Use of Laboratory Animals. All procedures were approved by the University of Miami Institutional Animal Care and Use Committee.

\subsection{Animal Husbandry}

In their natural habitat, marmosets live in social groups composed of an adult breeding pair and multiple offspring (Layne and Power, 2003). Animals in pairs and groups huddle and share body heat and are better able to tolerate cooler temperatures than a single animal (Layne and Power, 2003). In addition, pair-housed animals groom each other. If fur is neglected in pair-housed animals, it may indicate signs of withdrawal by the individual or its partner. In our study, the marmosets were housed together in a climate-controlled 
environment (temperature $76-82^{\circ} \mathrm{F}$ and relative humidity at $38-70 \%$ ), in their own twin or triplet groups (peer groups) prior to surgery. Their overall care was closely supervised by veterinary staff who performed regular physical examinations of animal behavior, body weight, and blood analysis. Whenever the animals were single housed due to experimental constraints, visual interactions with the other animals were allowed through the cages. The home cage size for NHP up to $1.5 \mathrm{~kg}$ recommended according to "the Guide" is $76.2 \mathrm{~cm}$ in height and $0.20 \mathrm{~m}^{2}$ of floor area per animal (Research and Press, 2011). Our cages were $78.7 \mathrm{~cm}$ in height with a floor area of $0.58 \mathrm{~m}^{2}$ for single housed monkeys and either doubled in height or floor area for pair or group housed monkeys. The home cages had racks placed side by side to ensure line of sight between and interaction with other peer groups even when single housed. In addition, the home cages were equipped with hideaway areas (e.g. tubes, buckets, sling beds) to provide the animals with sleeping areas and solitude spaces. We observed that some marmosets preferred to huddle in groups and sleep in the open at the back of the cage while others slept in their sleeping tubes. The marmosets were given environmental enrichments in the form of toys for play inside their cages and audio visual entertainment placed outside the cages. Reflective objects were hung on the cage as well. New animals were allowed to see the other animals being handled regularly, which expedited the training of naïve animals. Uneaten food and excreta were removed daily. Cages were rotated each fortnight for thorough cleaning.

\subsection{Animal Handling and Training}

\subsubsection{Treats}

Marmosets in the wild eat fruits and small insects. Their daily diet in the laboratory consisted of a combination of fresh fruits with dry and wet species-specific feed (ZuPreem and New World Primate Biscuit, Lab Diet 5040). They also had access to water ad libitum. We observed that marmosets were not willing to work for food that was included in their 
basic diet since no food/water restriction was done in our studies (We only used positive reinforcement protocols to shape their behavior). Rather, the marmosets were more motivated for sweet rewards such as marshmallows and Cheerios ${ }^{\mathrm{TM}}$ (fruity and banana nut in particular). However, when sweet foods are used as rewards it is important to monitor the teeth of the marmosets over time and whether or not the animals continue to eat their standard diet. In our experience, sometimes the animals were bored with the food and therefore different fruits were rotated on a monthly basis. Nuts, especially almonds, were particularly well received (Figure 2). When introducing new treats, stool and behavior was always monitored. We found that introducing a new treat was a multi-step process. In our experience, marmosets are risk-averse and (unlike macaques) will rarely simply taste a new food the first time it is offered even if they will enjoy that food later. This made it challenging initially to identify what food rewards were useful for treats during behavioral training. Animals often dropped the treat the first time they tasted it, regardless of that treat's future preference, and it was only after time that they discovered that they enjoy a novel treat. A new treat was simply left in the home cage so that naïve animals explored it at their own pace. Additionally, if naïve marmosets observed other marmosets consuming a treat, it helped them in feeling more comfortable towards it. Liquid based rewards were very popular: marmosets are sap eaters and have long tongues for obtaining sap from trees. Liquids were kept in a large $(60 \mathrm{ml})$ syringe with catheter tip and the monkeys used their tongue to obtain the reward. Juice rewards such as vanilla flavored rice milk, almond milk, strawberry flavored yogurt drink, and Ensure ${ }^{\circledR}$ were used. The preferences of each animal were identified during the initial familiarization phase, and we have found that the marmosets vary in which treats they particularly enjoy. For example, some of them had a strong dislike for strawberry flavored yogurt drink while others liked it very much. 


\subsubsection{Acclimating Marmosets to Human Interactions}

147

148

150

151

152

153

154

155

156

157

158

159

160

161

162

163

164

165

166

167

168

169

Gloves with puncture resistant fingertips and Kevlar lining were used for handling marmosets, especially during early training, since they have sharp teeth. Marmosets have scent glands and scent mark their environment (Sutcliffe and Poole, 1978). Therefore, handling gloves were hung or left in the home cages for the monkeys to smell and scent mark so they could become familiar with the gloves. Whenever handling the animals, they were rewarded by treats separate from their basic diet. Treats were also left on the gloves or other locations in the home cage so that the trainer could observe how the monkeys would consume the treats when the trainer moved away. When present, the trainer would observe and evaluate the animal's behavior and level of relaxation corresponding to his or her presence, how quickly the animals find and eat treats, and otherwise gauge how interactive they appeared to be. Treats were then offered inside the home cages, typically using forceps so the animals could acquire them without having to come to close to the trainer. Once the monkeys get more comfortable with the trainer, treats were eventually offered using gloved fingers. As the animals became more comfortable, they proactively came to the front part of the home cages to receive treats. At this point, the home cage door was opened and treats were offered on the palm of the gloved hand for the animals to come and eat. Most marmosets, once comfortable, were willing to come to the trainer and even sit on one palm and take treats from the other palm. Using a syringe with a liquid reward was useful at this stage to encourage the monkeys to become very comfortable being close to the trainer while drinking the reward, since they would stay in place and drink the liquid reward as opposed to taking the treat and eating it elsewhere. During this stage of training, it was important to avoid sudden movements or loud noises and to be consistent in the actions taken to offer treats. 


\subsubsection{Handling}

A 'scoop' was used for transferring monkeys between home cages and the marmoset chair (Figure 3A). We typically make the body of the scoop by modifying a 2-liter plastic water pitcher. The scoop was a well-ventilated, transparent plastic container that was large enough to comfortably hold a marmoset. Both ends could be closed using lids/doors and modified to suit our experimental setting from other such devices (Williams et al., 2008). The body of the scoop had a mesh grid on one side that enabled the monkeys to hold on to, as they like doing on the grid of their home cages. The scoop consisted of a handle for the trainer to hold and a large removable door panel on the side that can be opened to give the trainer access to the animal. The bottom of the scoop had a partial slit/opening to accommodate the long tails of the marmosets. Since our animals would have head implants, once they were trained using the grid scoop, we gradually allowed them be familiar with a different scoop without the grid, so that the head implants were not accidentally snared or caught in the grid after the surgery. In this new scoop, the grid was replaced with same material as the body of the scoop (i.e. nothing was cut out of the plastic).

For naïve monkeys, a scoop with both ends open was left inside the cage to allow the monkeys to explore it, play within it, and scent mark it. Treats were placed inside to encourage the animals to familiarize themselves with the scoop. This tended to happen within a few days, especially if the monkeys had seen other marmosets playing in the scoops. The scoops were often left in the cages overnight until the animals are comfortable going in and out of them. Once the animals were comfortable with the scoop, they were trained to enter the scoop when the trainer placed it in the home cage. The top lid of the scoop was closed and some treats were placed inside. By having the monkey situated between an open scoop and the experimenter's hand, it was easy to guide the animals to get into the scoop. Occasionally, animals would jump around the cage. However, animals would come inside the scoop for the treats placed inside. Once trained, they willingly walk in 
the scoop. As the monkeys entered the scoop, the bottom lid was closed and the scoop

197

198

199

200

201

202

203

204

205

206

207

208

209

210

removed from the cage. During this stage of training, it was again important to avoid any sudden movements and allow the monkeys to voluntarily enter the scoop. During initial scoop training, once the monkey entered the scoop they were kept in it briefly (few minutes) while being offered treats and then returned to the home cage and rewarded again. This was done several times a day until the monkeys were comfortable entering and exiting the scoop.

\subsubsection{Chairing and De-chairing}

Once the animal was comfortable with being 'scooped', they were acclimated to sitting in the marmoset chair, Figure 3B. The chair consisted of an adjustable waist ring, a neck plate, a foot plate and a seat belt (a simple Velcro ${ }^{\circledR}$ band) (Figure 3B). The chair was a modified version of the monkey chairs used in other experiments and was tailored to accommodate marmosets (Hearn, 1977; O'Byrne and Morris, 1988; Schultz-Darken et al., 2004). The height and alignment were adjusted so that the animal sat comfortably in an upright posture. Before chairing the animal, the foot plate was moved out of the way and a removable grid was attached for the animal to hold on. The seat belt and the neck plate held the animal gently in place and the foot plate made seating comfortable. The base of the chair was fixed on a movable and adjustable platform in order to transport monkeys between rooms and for adjusting height for experiments. Chair training was done once or twice a day until the monkeys were comfortable with the process. At the beginning of the chair training, since the animals were not used to coming out of the scoop, the experimenter's hand was used from the side to gently coax the animal to come out. For de-chairing the monkeys to return to their home cage, the chair was simply positioned at the door of the home cage and the neck plate and seat belt was loosened. The monkey would then climb up into the cage. The animal was rewarded again once it was back in the home cage. 


\subsubsection{Acclimation to the lab environment}

Once the monkeys were comfortable with chairing, they were brought in to the experimental room. The duration for which each animal was kept in the experimental room was gradually increased from a few minutes (on the first day) up to an hour. Marmosets have excellent hearing and external noises can disturb training. Therefore, a static noise generator was used as a background noise during training to train the monkeys to be less sensitive to the external noises. We have found that training marmosets in pairs was more effective than training animals individually, especially during the early training periods for naïve animals. Observing the behavior of the partner helped the other monkey settle more easily. Based on our observation, animals that were brought in the lab alone at the beginning of training were not explorative. On the other hand, animals that began training in pairs were more explorative, most likely due to the presence of another animal. This also allowed vocal communication between the monkeys to reduce stress. When one trainer was training both animals, there were pauses between training the first monkey while the second monkey was trained ( $<1 \mathrm{~min})$. This often motivated the first monkey to increase interactions with the trainer to receive more rewards. Additionally, if a monkey which was more experienced at a task was present, the naïve monkey learned the tasks more quickly by observing the experienced monkey perform the task.

\subsection{Behavioral Tasks}

\subsubsection{Basic Training}

Once the animal was comfortable with the laboratory environment, they were taught different tasks. The basic task was center-out reaching to targets. Marmosets tend to acquire objects using their mouth rather than hands. Marmosets do not have opposable thumbs (Stellar, 1960) and tend to grab things with their palm. For initial training, treats were given with a pair of forceps. Gradually, they were encouraged to reach with the hand 
and not the mouth or tongue. Studies have shown that the handedness of the marmosets depend on the posture (Box, 1977; Cameron and Rogers, 1999; Singer and Schwibbe, 1999; Hook and Rogers, 2000). In an upright seated posture, we were able to train all but one monkey to use the left hand to reach for targets. To encourage the use of the left hand, an elastic loop anchored to the chair was placed loosely around the right wrist. The loop didn't prevent movements but made right arm movements slightly more difficult than left arm movements, and thus the monkeys proactively learned to make reaching movements with their left hand. Out of the 12 animals, one animal was reluctant to work with the left hand as his right hand was the dominant hand. Hand dominance was generally determined by observing which hand the animal was more likely to use to reach for food. In that animal, we used the elastic loop on the left hand so that the animal reached with the right hand.

Our observation has been that the monkeys moved the forceps closer to themselves using the hand and then reached for it with the mouth. To avoid the use of the mouth to reach for food reward, we used a cubby hole device (a modified version of a Kluver board (Moore et grasp the food. Marshmallows were good food treats for this task.

In early sessions, the monkeys were trained to place their left hand on a touch pad for a variable hold time period to trigger an infrared (IR) beam (Figure 4B) which can be used as a start or stop marker for behavioral research. The touch pad had a plastic diffuser at which the animal comfortably rested the hand. A light was used under the plastic diffuser to aid the training. The plastic diffuser was lighted when the IR was not triggered. When the IR 
beam was triggered, the light went off with a corresponding audio cue. The monkeys were encouraged to reach, as before, to treats on a forceps. The touch pad was put in-between the forceps and the monkey's hand so that the animal triggered the IR beam every time it reached for the treat. When they understood the idea of the touch pad, treats were waved in front of them to encourage them to place their hand on the touch pad. Eventually, the monkeys learned that triggering the touch pad was rewarded. As time progressed, the touch pad was fixed to the chair, in the place where the animal rested its hand.

\subsubsection{Tasks}

We trained these monkeys for three different tasks.

Four target reaching task: The first task was 4-target reaching task using a device with a door ('door device'). The door device with four treats behind an opaque door was placed in front of the animal (Figure 4C). When the animal triggered the touch pad, the door was opened and it could see the treats in front and reached to one of the four targets. In our studies, we used this task for studying reward processing in the brain. The animals learned this quickly ( 1 week). Nothing additional was done besides identifying and using the treats they already liked.

Robot task (Go-no-Go and 2-target): The second task was a robot task which was introduced for performing BMI task and also study the interactions with the environment (Prins et al., 2013b). The robot task was of two kinds: a Go-no-Go paradigm and a 2-target reach task

(Figure 4D). For both tasks, the monkey triggered the touch pad and a robot appeared in front of the animal. The robot had the treats for the animal and this was used to train the animals for the BMI experiments. The animals had to either reach vs no reach for Go-no-Go, or reach left vs right for the 2-target reach task to receive food treats. The targets had 
by an audible success tone when the animal triggered the target or a failure tone if it failed

to do so within a certain time limit. The time limit was large at first ( $10 \mathrm{sec})$ and eventually they were trained to reach within $2 \mathrm{sec}$. The treats were placed on the robot and the animal quickly learned to associate the robot with the treats.

Touch Screen Task: The third task was a touch-screen task, where the monkey reached for a target on a touch-screen. The training was done by placing small pieces of marshmallow on the touch screen. Once the animal had the idea of reaching and touching a circle on the screen, the marshmallows were no longer put on the touch screen. An automatic liquid (rice milk) reward system was used for the trained animal. At present, only one monkey has been trained on the touch screen task, but he learned the task very quickly. Previous studies have been done in other labs in the home cage with touch screens (Crofts et al., 1999). It should be noted that the touch pad was a device to keep the hand on until the trials started. This was used as a start point for all trials. The touch screen on the other hand was similar to a tablet or a computer monitor.

\subsection{Neurosurgery Techniques}

The marmoset brain $(\sim 8 \mathrm{~g})$ is approximately 12 times smaller in volume than that of the rhesus macaque, and 180 times smaller than the human brain (Stephan et al., 1981). The relatively smooth topology of the cerebral cortex makes it easier to implant microelectrode arrays (MEAs) to target neural structures (Solomon and Rosa, 2015). Knowledge of the cortical organization in the small brain of the marmoset holds considerable interest in terms of understanding aspects of brain scaling within the order primates (Carlson et al., 1986; Preuss and Goldman-Rakic, 1991; Changizi and Shimojo, 2005; Palmer and Rosa, 2006; Burman et al., 2008). The marmoset brain has very few sulci and gyri, and can simplify access to cortical regions. Additionally, while the marmoset brain is larger than that of rats, it is still 
small enough to access deep brain structures. The frontal lobe of the marmoset contains the same basic subdivisions found in the much larger macaque brain and the motor and premotor cortices form a relatively large proportion of the frontal lobe (Burman et al., 2008; Paxinos et al., 2012).

\subsubsection{Anesthesia and Stereotaxic Approach} on the arms, tail, and head were shaven to allow easy application of electrocardiograph (EKG) leads and oxygen-saturation monitors which included end-tidal carbon dioxide monitoring. The animal was positioned in a standard stereotaxic frame (Kopf Instruments, Tujunga, CA) for small animals with ear bars and a bite bar. Eye lube was applied on eyes. In all our surgeries, we have found that the marmosets can be easily positioned on a stereotaxic frame suitable for rats. After the animal was positioned on the stereotaxic frame, the animal was draped sterilely and the surgical site on the head was thoroughly cleaned with multiple scrubs of Chlorhexidine, iodine and isopropyl alcohol. A midline incision was made from behind the orbital ridge to the interaural (IA) line. The subperiosteal soft tissues were dissected to expose the skull and the skull was cleaned with hydrogen peroxide. For our studies, the implant locations were the hand-arm region in the primary motor cortex (MI: AP+9.0mm and ML-4.5mm with $1.8 \mathrm{~mm}$ depth) and the striatum targeting the nucleus accumbens core (NAcc: $\mathrm{AP}+11.5 \mathrm{~mm}$ and $\mathrm{ML}-2.3 \mathrm{~mm}$ with $7.9 \mathrm{~mm}$ depth). These target 
locations were obtained from a detailed comparative analysis of the available stereotactic atlases for marmosets (Palazzi and Bordier, 2008; Newman et al., 2009; Yuasa et al., 2010; Hardman and Ashwell, 2012; Paxinos et al., 2012). All measurements were made relative to the inter-aural line. The surgical sites were marked at the above coordinates and 6-8 titanium anchoring screws (3/16" length \#00-90, SmallParts) were screwed into the skull. A craniotomy at each of the implant locations was made using a high-speed micro drill with drill bit (size\#65). Once the cortex was exposed, the dura was removed carefully using curved microscissors (Part No 15017-10, F.S.T., Foster City, CA). The isoflurane was reduced to $0.8 \%$ and the motor area was mapped for identifying the hand and arm region within the exposed MI region. Biphasic pulses of pulse width $100 \mu \mathrm{sec}$ and frequency $50 \mathrm{~Hz}$ was used to length with the tips $1 \mathrm{~mm}$ apart.

The MEA was placed on a micropositioner attached to the stereotaxic frame, which allowed the MEA was advanced was measured relative to the surface of the cortex. Electrophysiological monitoring was performed as the MEA was advanced into the cortex to further confirm the target implant location. Once the MEA reached the desired target depth, a small saline soaked piece of Gelfoam sponge was used to cover the craniotomy site around the MEA. A thick layer of dental acrylic was then used to anchor the electrodes with the corresponding anchoring screws. Similar procedures were followed for the second MEA. Once the arrays were all in place, the area was covered by dental acrylic. The acrylic was applied in layers until the connector base of the electrode arrays were embedded up to the 
top of the connectors in order to protect the arrays from breakage during the animal's normal head movements. Finally, a layer of antibiotic ointment (triple antibiotic ointment neomycin, polymyxin, bacitracin) was placed at the skull-scalp-acrylic interface. Where needed, the skin was sutured around the electrode pedestal using 5-0 nylon sutures and betadine/povidone iodine was applied to the sutured area to minimize infection. These sutures were removed 7-10 days following surgery.

\subsubsection{Recovery}

Postoperative care required ascertaining cardiopulmonary stability, glucose monitoring, and careful temperature monitoring. The animals were returned to their home cages after they recovered from anesthesia and became mobile. They were constantly monitored during the next several days and special attention was paid to their diet, hydration and excretory feces. During this time, they were also offered more treats, rice milk, and Ensure to help them recover quickly. Post the implant surgery, the animals were single housed to prevent other animals from interfering with the head implant. Post operatively analgesics and antibiotics were administered. Cephalexin (20mg/kg orally twice daily for 5 days), buprenorphine (0.001-0.015 mg/kg IM twice daily for 2 days, IM), triple antibiotic ointment (as prescribed by the veterinarian) were used during the post-surgical recovery period. As with most surgeries, our observation has been that with shorter surgery duration, the animals wake up faster (usually within 15-30 minutes) after anesthesia removal, start to eat treats once they wake up, and recovery in general is faster. The animals also move around their cage after surgery and start to eat their regular diet soon after surgery. All recordings begin once the animal has completely recovered from the surgery (usually 2-3 weeks post-surgery).

\section{Results}




\subsection{Variability across animals}

397

400

401

402

403

404

405

406

407

408

409

410

412

413

414
As discussed before, wherever possible, we worked with the animals in pairs. This encouraged animals to acquire new tasks faster when watching their counterpart. Younger marmosets were easier to work with and easier to train than older marmosets. For example, animals N3, N4, N9, and N10 were older than 33 months when the experimental training began (considered as 'older' animals in comparison to others). Animals N5, N6, N7, N8, N11 and N12 were 26, 19 and 21 months respectively and were considered 'younger' in comparison to others. The treat preferences for each animal were also varied. For all of them, wax worms were the preferred treat while the second preferred treat was mushrooms for some and marshmallows for others. The experiments usually started with the less desirable treat and moved on to more desirable treats to lengthen the session. The treats were presented in a pseudo-random order (more of the less desirable treats at the beginning). The size of the treats given also had an impact on the number of trials per session and number of trials per session was limited. Results presented here are from 12 animals. Ten animals had reached maturity (18-24 months) upon arrival and weighed $330 \pm 63.82 \mathrm{~g}$. They were $391 \pm 45.33 \mathrm{~g}$ at the time of surgical procedure. Two monkeys were 17-18 months upon arrival, weighing $155 \pm 7.07 \mathrm{~g}$ and they were $210 \pm 28.28 \mathrm{~g}$ in weight 3 months later (N11 and N12).

\subsection{Training}

The time period taken by our animals to learn different tasks are provided in Figure 5 which shows variability among animals. Five of the basic training milestones are shown in Figure 5 for 12 monkeys. Each animal had its own training timeline but not all animals were trained for the 4-target reach task. Monkeys trained in pairs are shown in same color, lighter and darker. The tasks on $\mathbf{x}$-axis are as shown in Table 1. 
Upon learning the touch pad, we trained the animals for different tasks and the times taken are given with each task description in Table 2 .

The variability for each animal is noteworthy. Animals trained in pairs (same color, lighter and darker) have similar timelines. For N3 and N4 pair, chair training was more difficult at first and lack of personnel resulted in training less than 5 days a week which contributed towards the longer chair training times. For these two monkeys the chair training was combined with giving treats while in chair. The extensive time for chair training resulted in N12, the free reaching period was longer than others and hence, the touch pad was introduced before they had learned to reach freely while sitting in the chair. The touch pad aided in free reaching at this point. N5 and N6 took longer to be familiar with the idea of the go-no-go robot task. However, since N4 and N6 were already trained on the go-no-go robot task, they learned the two target robot task much faster than those who did not do the gono-go task. For N8 the training time was split in two while the other animals were being trained. There was approximately a down time of 3 months and once we started to train again, the process had to be taught from the beginning, which contributed to the very high training time (double of that of N7 and N9) for N8. We only trained N6 on the touch screen task and the animal learned to associate the touching the touch screen with the receiving of reward very fast ( 1 week). It took another week to train him to touch a moving target and hold for $500 \mathrm{msec}$. Animal N10 is being currently trained.

The number of useful trials (animal paying attention) per session (when fully trained) varied with each animal, as did the length of the session (Figure 6). The animals that had more trials per session worked for a mixture of solid and liquid rewards which may have increased the time/trials per session. N6 completed a maximum of 110 trials per session (rice milk and mushrooms) for the touch screen moving target (touch screen task not shown in figure). The 
missing numbers on the figure were data not recorded during the training times or animals not trained for the particular task.

Figure $6 \mathrm{~A}$ shows the maximum number of trials per session. However, on some days the animals would be distracted by outside momentary noise and it was difficult to get the animal to concentrate on the task and the session had to be ended earlier than usual. Figure $6 \mathrm{~B}$ shows the maximum useful recording session length per monkey for the tasks they performed. Since the 4-target reach task was simple and the animals received an immediate reward (as opposed to waiting for the robot), it was easier to get longer sessions during this task. The animals that tended to work faster would have higher trials per session but tend to get full faster and therefore work shorter length of time (eg N6).

\subsection{Neurophysiological Recordings}

Neural data was recorded from 16-channel tungsten microwire arrays, (Tucker Davis Technologies, Alachua FL) and floating microelectrode array, (MicroProbes, Gaithersburg, MD). Neural recordings were collected using a Tucker Davis Technologies RZ2 system sampling at $24,414 \mathrm{~Hz}$ and a band-pass filter $300-5000 \mathrm{~Hz}$. Local Field Potentials (LFPs) were acquired with a $1-500 \mathrm{~Hz}$ band-pass filter. Figure 7 shows recordings from 3 electrodes each for NAcc and MI (N4), 2 months after implantation. A common average reference (CAR) was used to improve signal quality during post-op recordings (Ludwig et al., 2009). The CAR was set up in such a way that if the signal to noise ratio (SNR) needed to be further improved, any of the electrodes could be removed from the CAR. This was necessary as the SNR varies with the electrode longevity and encapsulation (Ludwig et al., 2006; Ludwig et al., 2009; Prasad and Sanchez, 2012).

Figure 8 shows the longevity of each array (NAcc and $\mathrm{MI}$ ) for 6 monkeys that underwent implantation surgery. Array longevity was defined as the time duration during which the electrodes within the implanted electrode array produced viable electrophysiological 
recordings (single unit action potentials). In most cases the failures occurred to the connector junction, with it wearing out from repeated, daily use. For monkeys N3 and N4 recordings of both arrays lasted up to elective terminal procedure. Meanwhile, for N2 and $\mathrm{N9}$, only the $\mathrm{MI}$ arrays lasted up to elective terminal procedure while the NAcc arrays failed and therefore recordings stopped prior to the end of the experiment. For N7 both arrays failed before the end of the experiment. Monkey N10 only had one implant and is still being recorded.

\section{Discussion}

We have shown that common marmoset (Callithrix jacchus) can be used as a smaller NHP model for behavioral neuroscience studies. Due to their reproductive rate, more animals can be used to rapidly generate data to test for reproducibility. While they are not as adept at dexterous tasks as larger NHP models such as macaques, they still serve as an excellent alternate NHP model for behavioral neuroscience studies due to their small size, ease of handling, cognitive abilities, and similarities to other primate motor systems (Okano et al., 2012). While larger animals can be used for complicated behavioral tasks, we have shown that a smaller animal model can also be used for several behavioral tasks. The marmosets are easier to handle and can be trained on basic tasks (touching a target, choosing between targets, reaching for objects, etc.) easily. Marmosets do not have individual finger dexterity like macaques and cannot be used for tasks that require individual digits. However, their palms are large enough to trigger a touch pad or hold a joystick. In an upright seated posture, we were able to train all the monkeys to work with their left hands even though in their home cage, they used both arms to reach for food. In all our studies, we used positive reinforcement for training and none of the animals were food or liquid restricted. Neural and behavioral recordings were performed once or twice a day and they were done very early in the day before their regular diet feeding time (if trained once a day). During the 
recording sessions, animals continuously received a variety of food treats. Each

496

497

498

499

501

502

503

504

505

506

507

508

509

510

511

512

513

514

515

516

517

518

519

recording/training session lasted between 30-75 minutes and always ended with a positive reward to reinforce good behavior. We discuss below some of the issues that we overcame using a new animal model for behavioral research and share our experience with this animal model with a goal to help other laboratories intending to use this model in their research.

Food treats and experimental session duration: Marmosets feed primarily on gum, eat small insects, and various fruits in the wild. We found that each animal had a taste preference for one or more food treats. This is challenging in the initial training and acclimation period when one has to identify if the animals preferred a particular treat. However, after several iterations with various food treats, we found that all the animals liked waxworms. They also liked fresh mushrooms, which can be used as a low sugar treat. Since the marmosets are small animals, food rewards were kept to small sizes: a standard mini marshmallow was usually cut into at least 6-8 pieces and mushrooms were cut into pieces of size approximately $2 \times 4 \times 4 \mathrm{~mm}$ (Figure 2 ). If the size of the reward does not affect the experiment, smaller treats can be used at the beginning of the session, and slightly bigger treats towards the end to maximize the experiment duration. We were able to obtain approximately $30-90$ trials in each session. Liquid reward in small amounts can also be used to maximize the time. However, we did not rely heavily on liquid rewards for any animal.

Intubation and Anesthesia: For the first few monkeys, we used intubation and Constant Rate Infusion (CRI) ketamine was used to maintain anesthesia $(20-30 \mathrm{mg} / \mathrm{kg} / \mathrm{hr}$ ) after induction with ketamine-xylazine $(10-15 \mathrm{mg} / \mathrm{kg})$. The esophagus of the marmosets is very small and it is challenging to insert an intubation tube in the trachea. Finding the right size of tube for intubation is critical as a large and less flexible (more rigid) can damage the trachea and compromise respiratory function. We used a $2.0 \mathrm{~mm}$ uncuffed endotracheal tube (A.M. Bickford, Wales Center, NY). Another critical factor when performing endotracheal 
intubation in marmosets is the distance that the tube needs to be inserted in the trachea. Based on our experience, this distance ranged between $5-6 \mathrm{~cm}$. We also had to make sure that the tube remained stable and did not move during the placement into the stereotaxic frame. Moreover, the endotracheal intubation procedure was time consuming and prolonged the anesthetic time. We continuously tried to optimize our surgical methods to reduce surgical duration. Therefore, in the last 3 monkeys we changed our anesthesia procedure from CRI ketamine infusion to only isoflurane anesthesia. We also stopped intubation as it did not provide any significant advantage for our specific surgery. The final procedure listed in 2.4.1 was what we used with the last 3 monkeys, where the intubation was replaced with a custom-made nose cone attached to the stereotactic frame that was used to deliver the isoflurane gas anesthesia. Removing the endotracheal intubation component, significantly reduced the surgery time and reduced anesthesia complications. Shorter surgery times also contributed to improved recovery times. In the first few surgeries, 2 catheters were used: one of which was dedicated for the ketamine infusion and the other was used for injecting drugs as needed during the surgery. However, in our current procedure where we use gas anesthesia, we use only one catheter for fluids or emergency Stereotaxic coordinates: Stereotaxic coordinates relative to bregma were used for the first few animals, but there was much variability in the location of bregma from one animal to another and also from one atlas to another. There was lesser variability in the atlases when identifying coordinates relative to the interaural plane. The bregma in some animals were located very caudal and the midline incision needed to be longer to identify the bregma. Secondly, removing the step of identifying the bregma also reduced the surgery duration. Therefore, all surgical coordinates as given in section 3.3 were made relative to interaural plane. 
In this study, we proposed the marmoset as a new model for behavioral neuroscience research that can be used as a smaller alternative primate model compared to larger primate models. While these animals lack the dexterity that larger primate models possess, all animals were able to learn behavioral tasks that involved forelimb reaching in varied forms of complexity. We presented detailed experimental details based upon our experience working with this animal model so that similar or modified procedures can be adapted by other laboratories intending to work with this model.

\section{References}

Abbott DH, Barnett DK, Colman RJ, Yamamoto ME, Schultz-Darken NJ (2003) Aspects of common marmoset basic biology and life history important for biomedical research. Comparative medicine 53:339-350.

Antunes SG, de Groot NG, Brok H, Doxiadis G, Menezes AA, Otting N, Bontrop RE (1998) The common marmoset: a new world primate species with limited Mhc class II variability. Proceedings of the National Academy of Sciences 95:11745-11750.

Bert A, Abbott DH, Nakamura K, Fuchs E (2012) The marmoset monkey: a multi-purpose preclinical and translational model of human biology and disease. Drug discovery today 17:1160-1165.

Bowes C, Burish M, Cerkevich C, Kaas J (2013) Patterns of cortical reorganization in the adult marmoset after a cervical spinal cord injury. The Journal of comparative neurology.

Box HO (1977) Observations on spontaneous hand use in the common marmoset (Callithrix jacchus). Primates 18:395-400.

Burman KJ, Palmer SM, Gamberini M, Spitzer MW, Rosa MG (2008) Anatomical and physiological definition of the motor cortex of the marmoset monkey. Journal of Comparative Neurology 506:860-876.

Cameron R, Rogers L (1999) Hand preference of the common marmoset (Callithrix jacchus): problem solving and responses in a novel setting. Journal of Comparative Psychology 113:149. 
570

571

572

573

574

575

576

577

578

579

580

581

582

583

584

585

586

587

588

589

590

591

592

593

Carlson M, Huerta M, Cusick C, Kaas J (1986) Studies on the evolution of multiple somatosensory representations in primates: the organization of anterior parietal cortex in the New World Callitrichid, Saguinus. Journal of Comparative Neurology 246:409-426.

Carrion R, Patterson JL (2012) An animal model that reflects human disease: the common marmoset (Callithrix jacchus). Current opinion in virology 2:357-362.

Changizi MA, Shimojo S (2005) Parcellation and area-area connectivity as a function of neocortex size. Brain, Behavior and Evolution 66:88-98.

Choi JY, Takahashi DY, Ghazanfar AA (2015) Cooperative vocal control in marmoset monkeys via vocal feedback. Journal of neurophysiology 114:274-283.

Crofts H, Muggleton N, Bowditch A, Pearce P, Nutt D, Scott E (1999) Home cage presentation of complex discrimination tasks to marmosets and rhesus monkeys. Laboratory Animals $33: 207-214$.

Cyranoski D (2009) Marmoset model takes centre stage.

Cyranoski D (2014) Marmosets are stars of Japan's ambitious brain project. Nature 514:151-152.

Eliades SJ, Miller CT (2016) Marmoset Vocal Communication: Behavior and Neurobiology. Developmental Neurobiology.

Elston GN, Jelinek HF (2001) Dendritic branching patterns of pyramidal cells in the visual cortex of the New World marmoset monkey, with comparative notes on the Old World macaque monkey. Fractals 9:297-303.

Fouad K, Klusman I, Schwab M (2004) Regenerating corticospinal fibers in the Marmoset (Callitrix jacchus) after spinal cord lesion and treatment with the anti - Nogo - A antibody IN - 1. European Journal of Neuroscience 20:2479-2482.

Hardman CD, Ashwell KW (2012) Stereotaxic and chemoarchitectural atlas of the brain of the common marmoset (Callithrix jacchus): CRC Press. 
Harris RA, Tardif SD, Vinar T, Wildman DE, Rutherford JN, Rogers J, Worley KC, Aagaard KM (2014) Evolutionary genetics and implications of small size and twinning in callitrichine primates. Proceedings of the National Academy of Sciences 111:1467-1472.

Hearn JP (1977) Restraining device for small monkeys. Laboratory Animals 11:261-262.

Hearn JP (1983) The common marmoset (Callithrix jacchus). In: Reproduction in New World Primates, pp 181-215: Springer.

Hook M, Rogers L (2000) Development of hand preferences in marmosets (Callithrix jacchus) and effects of aging. Journal of Comparative Psychology 114:263.

Iwanami A, Yamane J, Katoh H, Nakamura M, Momoshima S, Ishii H, Tanioka Y, Tamaoki N, Nomura T, Toyama Y (2005) Establishment of graded spinal cord injury model in a nonhuman primate: the common marmoset. Journal of neuroscience research 80:172-181.

Jagessar SA, Fagrouch Z, Heijmans N, Bauer J, Laman JD, Oh L, Migone T, Verschoor EJ, Bert A (2013) The different clinical effects of anti-BLyS, anti-APRIL and anti-CD20 antibodies point at a critical pathogenic role of $\gamma$-herpesvirus infected B cells in the marmoset EAE model. Journal of Neuroimmune Pharmacology 8:727-738.

Jagessar SA, Kap YS, Heijmans N, van Driel N, van Straalen L, Bajramovic JJ, Brok HP, Blezer EL, Bauer J, Laman JD (2010) Induction of progressive demyelinating autoimmune encephalomyelitis in common marmoset monkeys using MOG34-56 peptide in incomplete freund adjuvant. Journal of Neuropathology \& Experimental Neurology 69:372-385.

Kajikawa Y, Lisa A, Blumell S, Sterbing-D’Angelo SJ, D’Angelo W, Camalier CR, Hackett TA (2008) Coding of FM sweep trains and twitter calls in area CM of marmoset auditory cortex. Hearing research 239:107-125.

Kap YS, Laman JD, A`t Hart B (2010) Experimental autoimmune encephalomyelitis in the common marmoset, a bridge between rodent EAE and multiple sclerosis for immunotherapy development. Journal of Neuroimmune Pharmacology 5:220-230. 
Kishi N, Sato K, Sasaki E, Okano H (2014) Common marmoset as a new model animal for neuroscience research and genome editing technology. Development, growth \& differentiation 56:53-62.

Kobayashi Y, Okada Y, Itakura G, Iwai H, Nishimura S, Yasuda A, Nori S, Hikishima K, Konomi T, Fujiyoshi K (2012) Pre-evaluated safe human iPSC-derived neural stem cells promote functional recovery after spinal cord injury in common marmoset without tumorigenicity. PloS one 7:e52787.

Kondo T, Yoshihara Y, Yoshino-Saito K, Sekiguchi T, Kosugi A, Miyazaki Y, Nishimura Y, Okano HJ, Nakamura M, Okano H (2015) Histological and electrophysiological analysis of the corticospinal pathway to forelimb motoneurons in common marmosets. Neuroscience research 98:35-44.

Layne DG, Power RA (2003) Husbandry, handling, and nutrition for marmosets. Comparative medicine 53:351-359.

Ludwig KA, Uram JD, Yang J, Martin DC, Kipke DR (2006) Chronic neural recordings using silicon microelectrode arrays electrochemically deposited with a poly (3, 4ethylenedioxythiophene)(PEDOT) film. Journal of neural engineering 3:59.

Ludwig KA, Miriani RM, Langhals NB, Joseph MD, Anderson DJ, Kipke DR (2009) Using a common average reference to improve cortical neuron recordings from microelectrode arrays. Journal of neurophysiology 101:1679-1689.

Miller CT, Freiwald WA, Leopold DA, Mitchell JF, Silva AC, Wang X (2016) Marmosets: A Neuroscientific Model of Human Social Behavior. Neuron 90:219-233.

Moore TL, Killiany RJ, Pessina MA, Moss MB, Rosene DL (2010) Assessment of motor function of the hand in aged rhesus monkeys. Somatosensory \& motor research 27:121-130.

Nash J, Fox S, Henry B, Hill M, Peggs D, McGuire S, Maneuf Y, Hille C, Brotchie J, Crossman A (2000) Antiparkinsonian actions of ifenprodil in the MPTP-lesioned marmoset model of Parkinson's disease. Experimental neurology 165:136-142. 
645

646

647

648

649

650

651

652

653

654

655

656

657

658

659

660

661

662

663

664

665

666

667

668

669

670

Newman JD, Kenkel WM, Aronoff EC, Bock NA, Zametkin MR, Silva AC (2009) A combined histological and MRI brain atlas of the common marmoset monkey, Callithrix jacchus. Brain research reviews 62:1-18.

O'Byrne K, Morris K (1988) A restraint system for the common marmoset (Callithrix jacchus). Laboratory Animals 22:148-150.

Okano H, Mitra P (2015) Brain-mapping projects using the common marmoset. Neuroscience research 93:3-7.

Okano H, Miyawaki A, Kasai K (2015) Brain/MINDS: brain-mapping project in Japan. Phil Trans R Soc B 370:20140310.

Okano H, Hikishima K, Iriki A, Sasaki E (2012) The common marmoset as a novel animal model system for biomedical and neuroscience research applications. In: Seminars in Fetal and Neonatal Medicine, pp 336-340: Elsevier.

Palazzi X, Bordier N (2008) The marmoset brain in stereotaxic coordinates: Springer.

Palmer SM, Rosa MG (2006) Quantitative analysis of the corticocortical projections to the middle temporal area in the marmoset monkey: evolutionary and functional implications. Cerebral Cortex 16:1361-1375.

Paxinos G, Watson C, Petrides M, Rosa M, Tokuno H (2012) The marmoset brain in stereotaxic coordinates: Elsevier.

Philippens IH, A`t Hart B, Torres G (2010) The MPTP marmoset model of Parkinsonism: a multipurpose non-human primate model for neurodegenerative diseases. Drug discovery today 15:985-990.

Pohlmeyer EA, Mahmoudi B, Geng SJ, Prins NW, Sanchez JC (2014) Using Reinforcement Learning to Provide Stable Brain-Machine Interface Control Despite Neural Input Reorganization. Plos One 9.

Prasad A, Sanchez JC (2012) Quantifying long-term microelectrode array functionality using chronic in vivo impedance testing. Journal of Neural Engineering 9:026028. 
671 Preuss TM, Goldman - Rakic PS (1991) Ipsilateral cortical connections of granular frontal cortex in

672 the strepsirhine primate Galago, with comparative comments on anthropoid primates.

673 Journal of Comparative Neurology 310:507-549.

674 Prins N, Sanchez J, Prasad A (2014) A confidence metric for using neurobiological feedback in actor-

675 critic reinforcement learning based brain-machine interfaces. Name: Frontiers in

$676 \quad$ Neuroscience 8:111.

677 Prins NW, Geng S, Pohlmeyer EA, Mahmoudi B, Sanchez JC (2013a) Feature Extraction and

678 Unsupervised Classification of Neural Population Reward Signals for Reinforcement Based

679 BMI. In: Engineering in Medicine and Biology Society (EMBC), 2013 Annual International

$680 \quad$ Conference of the IEEE: IEEE.

681 Prins NW, Geng S, Pohlmeyer EA, Prasad A, Sanchez JC (2013b) Representation of natural arm and

682 robotic arm movement in the striatum of a marmoset engaged in a two choice task. In:

$683 \quad$ Neural Engineering (NER), 2013 6th International IEEE/EMBS Conference on, pp 399-402:

$684 \quad$ IEEE.

685 Research IfLA, Press NA (2011) Guide for the care and use of laboratory animals: National Academies

$686 \quad$ Press.

687 Roe AW, Fritsches K, Pettigrew JD (2005) Optical imaging of functional organization of V1 and V2 in

688 marmoset visual cortex. The Anatomical Record Part A: Discoveries in Molecular, Cellular, 689 and Evolutionary Biology 287:1213-1225.

690 Santana MB, Halje P, Simplício H, Richter U, Freire MAM, Petersson P, Fuentes R, Nicolelis MA (2014)

691 Spinal cord stimulation alleviates motor deficits in a primate model of Parkinson disease.

$692 \quad$ Neuron 84:716-722.

693 Sasaki E, Suemizu H, Shimada A, Hanazawa K, Oiwa R, Kamioka M, Tomioka I, Sotomaru Y, Hirakawa

694 R, Eto T (2009) Generation of transgenic non-human primates with germline transmission.

$695 \quad$ Nature 459:523-527. 
Schorscher-Petcu A, Dupré A, Tribollet E (2009) Distribution of vasopressin and oxytocin binding sites in the brain and upper spinal cord of the common marmoset. Neuroscience letters 461:217222.

Schultz-Darken N, Pape R, Tannenbaum P, Saltzman W, Abbott D (2004) Novel restraint system for neuroendocrine studies of socially living common marmoset monkeys. Laboratory Animals 38:393-405.

Sequencing TMGAC (2014) The common marmoset genome provides insight into primate biology and evolution. Nature genetics 46:850-857.

Simões CS, Vianney P, De Moura MM, Freire MAM, Mello LE, Sameshima K, Araújo JF, Nicolelis MA, Mello CV, Ribeiro S (2010) Activation of frontal neocortical areas by vocal production in marmosets. Frontiers in integrative neuroscience 4:123.

Singer SS, Schwibbe MH (1999) Right or left, hand or mouth: Genera-specific preferences in marmosets and tamarins. Behaviour 136:119-145.

Smith D, Trennery P, Farningham D, Klapwijk J (2001) The selection of marmoset monkeys (Callithrix jacchus) in pharmaceutical toxicology. Laboratory Animals 35:117-130.

Solomon SG, Rosa MG (2015) A simpler primate brain: the visual system of the marmoset monkey. What can simple brains teach us about how vision works:136.

Stellar E (1960) The marmoset as a laboratory animal: maintenance, general observations of behavior, and simple learning. Journal of comparative and physiological psychology 53:1.

Stephan H, Frahm H, Baron G (1981) New and revised data on volumes of brain structures in insectivores and primates. Folia primatologica 35:1-29.

Sutcliffe A, Poole T (1978) Scent marking and associated behaviour in captive common marmosets (Callithrix jacchus jacchus) with a description of the histology of scent glands. Journal of Zoology 185:41-56.

Tardif SD, Mansfield KG, Ratnam R, Ross CN, Ziegler TE (2011) The marmoset as a model of aging and age-related diseases. ILAR Journal 52:54-65. 
722

723

724

725

726

727

728

729

730

731

732

733

734

735

736

737

Tokuno H, Watson C, Roberts A, Sasaki E, Okano H (2015) Marmoset neuroscience. Neuroscience research 93:1.

Troilo D, Rowland HC, Judge SJ (1993) Visual optics and retinal cone topography in the common marmoset (Callithrix jacchus). Vision research 33:1301-1310.

Van Vliet SA, Vanwersch RA, Jongsma MJ, Van der Gugten J, Olivier B, Philippens IH (2006) Neuroprotective effects of modafinil in a marmoset Parkinson model: behavioral and neurochemical aspects. Behavioural pharmacology 17:453-462.

Van Vlieta S, Blezer E, Jongsma M, Vanwersch R, Olivier B, Philippens I (2008) Exploring the neuroprotective effects of modafinil in a marmoset Parkinson model with immunohistochemistry, magnetic resonance imaging and spectroscopy. Brain research 1189:219-228.

Walker J, MacLean J, Hatsopoulos NG (2016) The Marmoset as a Model System for Studying Voluntary Motor Control. Developmental Neurobiology.

Williams PT, Poole MJ, Katos AM, Hilmas CJ (2008) A new device for the capture and transport of small nonhuman primates in scientific research. Lab animal 37:116.

Yuasa S, Nakamura K, Kohsaka S (2010) Stereotaxic atlas of the marmoset brain. 


\section{Legends}

Table 1: Definition of the basic tasks during the training

Table 2: Definitions of the advanced tasks trained for the monkeys and the time it took for each animal

Figure 1: PubMed Articles Corresponding to "marmoset brain" from 1968 to 2016

Figure 2: An example of monkey treats.

Figure 3: (A) Schematic of the Scoop for handling the monkeys. (B) Schematic of the Custom Made Marmoset Chair. Not to scale. Dimensions in mm. Attachment mechanisms (screws etc) not shown.

Figure 4: Devices for Training. (A) Cubby Hole device. (B) Touch Pad. (C) Door Device. (D) Robot Task. Not to scale. Dimensions in mm. Attachment mechanisms (screws etc) not shown. (E) 2-target Robot task. (i) animal keeps hand in touch pad to initiate the trial. (ii) once the trial is initiated, one of the targets (left) lights up and the robot comes out holding a treat. (iii) animal reaches and triggers the left target. (iv) robot moves to the left and the animal gets a reward.Not to scale. Dimensions in $\mathrm{mm}$. Attachment mechanisms (screws etc) not shown.

Figure 5: Training Times for different animals on different tasks in weeks. Monkeys trained in pairs are shown in same color, lighter and darker.

Figure 6: (A) Trails per session when fully trained and (B) Length of time per session for each animal. *Animals N11 and N12 are being trained at present and the values shown are the present values.

Figure 7: NAcc and MI recordings from 3 electrodes each (spike sorted manually) from animal N4, 2 months after implant

Figure 8: NAcc and MI longevity (in months) of the recordings for 6 monkeys. *Animal N10: the array is still intact and is being recorded from (6 months so far). 


\begin{tabular}{|c|c|}
\hline Task & Definition \\
\hline Scoop Trained & $\begin{array}{l}\text { Animal is comfortable getting into the scoop and the process takes less } \\
\text { than } 5 \mathrm{~min} .\end{array}$ \\
\hline Chair Trained & $\begin{array}{c}\text { Animal is comfortable sitting in chair and is not agitated or vocalizing for at } \\
\text { least } 15 \mathrm{~min} .\end{array}$ \\
\hline $\begin{array}{l}\text { Free Reaching (once } \\
\text { in the experimental } \\
\text { environment) }\end{array}$ & $\begin{array}{l}\text { Animal learned to reach with hands and take treat into mouth while seated } \\
\text { in the chair instead of reaching with its mouth or tongue. }\end{array}$ \\
\hline Touch Pad Trained & $\begin{array}{l}\text { Animal learned to associate keeping hand on the Touch Pad for a hold } \\
\text { period of } 700-1200 \mathrm{msec} \text { and audible reward tone. }\end{array}$ \\
\hline 4 target door device & $\begin{array}{l}\text { Animal can and is willing to reach to all } 4 \text { target locations when they } \\
\text { contained a reward. }\end{array}$ \\
\hline
\end{tabular}




\begin{tabular}{|c|c|c|}
\hline Task & Definition & Time in weeks \\
\hline $\begin{array}{l}\text { Go-no-Go } \\
\text { (robot) task }\end{array}$ & $\begin{array}{l}\text { Animal learned that there were two options and cues to } \\
\text { either reach or not reach when red (go) or green (no-go) light } \\
\text { came on and performed the appropriate action } 80 \% \text { of the } \\
\text { time to receive reward by robot. }\end{array}$ & $\begin{array}{l}\text { N3- } 1.00 \\
\text { N4- } 1.43 \\
\text { N5- } 5.57 \\
\text { N6- } 6.57\end{array}$ \\
\hline $\begin{array}{c}\text { 2-target (robot) } \\
\text { task }\end{array}$ & $\begin{array}{l}\text { Animal learned that there were two options (left and right) to } \\
\text { reach to two targets when either left or right cues were } \\
\text { shown to receive reward and performs the appropriate action } \\
80 \% \text { of the time to receive reward by robot. }\end{array}$ & $\begin{array}{c}\text { N4- } 3.14 \\
\text { N6- } 9.14 \\
\text { N7- } 16.57 \\
\text { N8- } 36.43 \\
\text { N9- } 17.71\end{array}$ \\
\hline $\begin{array}{l}\text { Catch trials } \\
\text { Trained }\end{array}$ & $\begin{array}{l}\text { To study non-rewarded behavior we used "Catch" trials, } \\
\text { where the monkey's correct action was not rewarded by the } \\
\text { robot. The animal learned that the "Catch" trials was a } \\
\text { mistake made by the robot and not himself. Catch trials at 15- } \\
20 \% \text { and the animal not getting agitated was considered } \\
\text { successfully trained. }\end{array}$ & $\begin{array}{l}\text { N3- } 0.71 \\
\text { N4- } 0.14 \\
\text { N6- } 0.14\end{array}$ \\
\hline \multirow{2}{*}{$\begin{array}{c}\text { Touch screen } \\
\text { task }\end{array}$} & Associate the touching of touch screen and reward. & N6- 1.00 \\
\hline & Touch a moving target. & N6- 1.00 \\
\hline
\end{tabular}




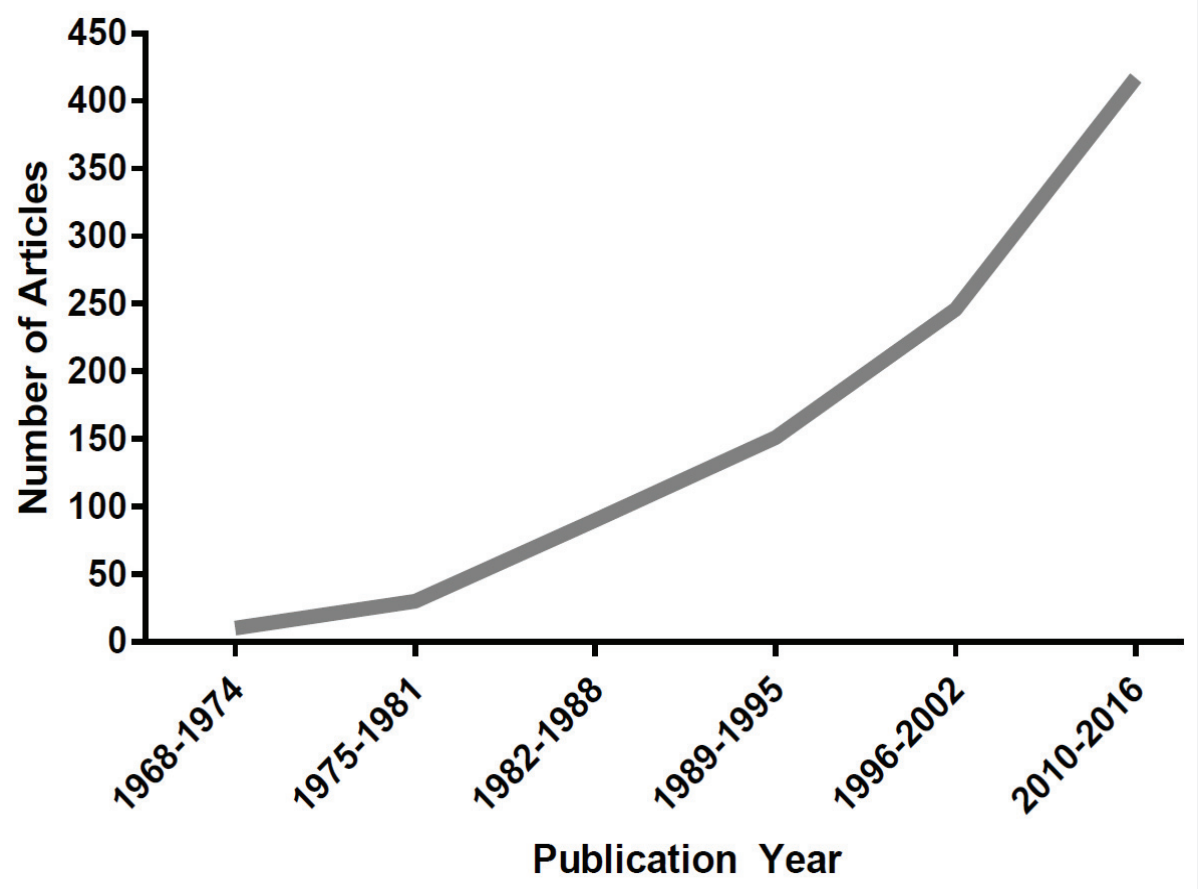

Figure 1: PubMed Articles Corresponding to "marmoset brain" from 1968 to 2016 


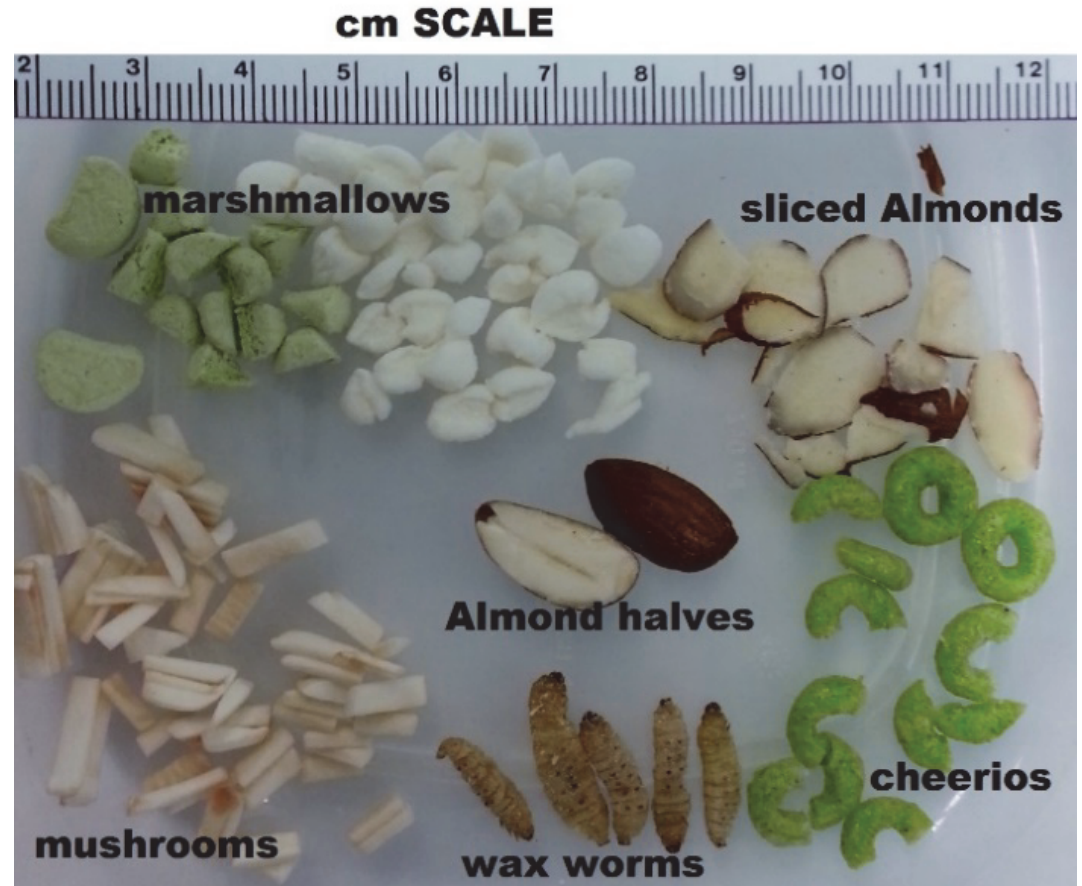

Figure 2: An example of monkey treats. 
(A)
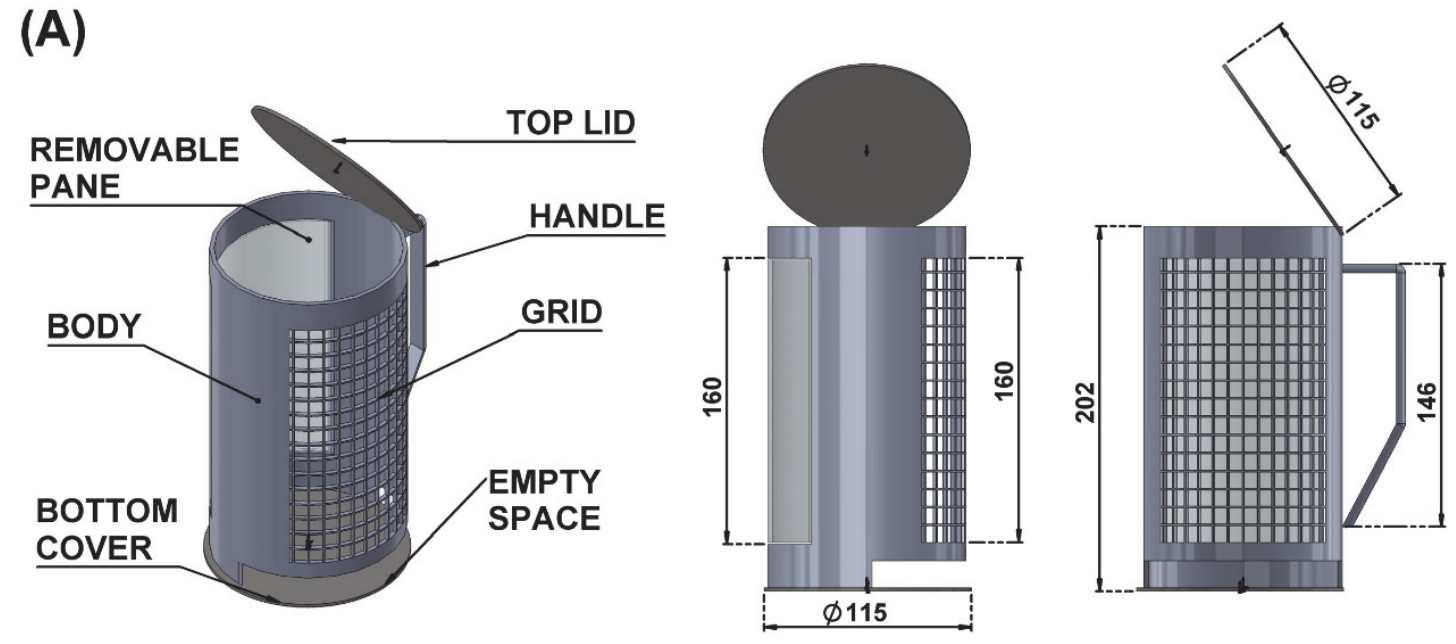

(B)

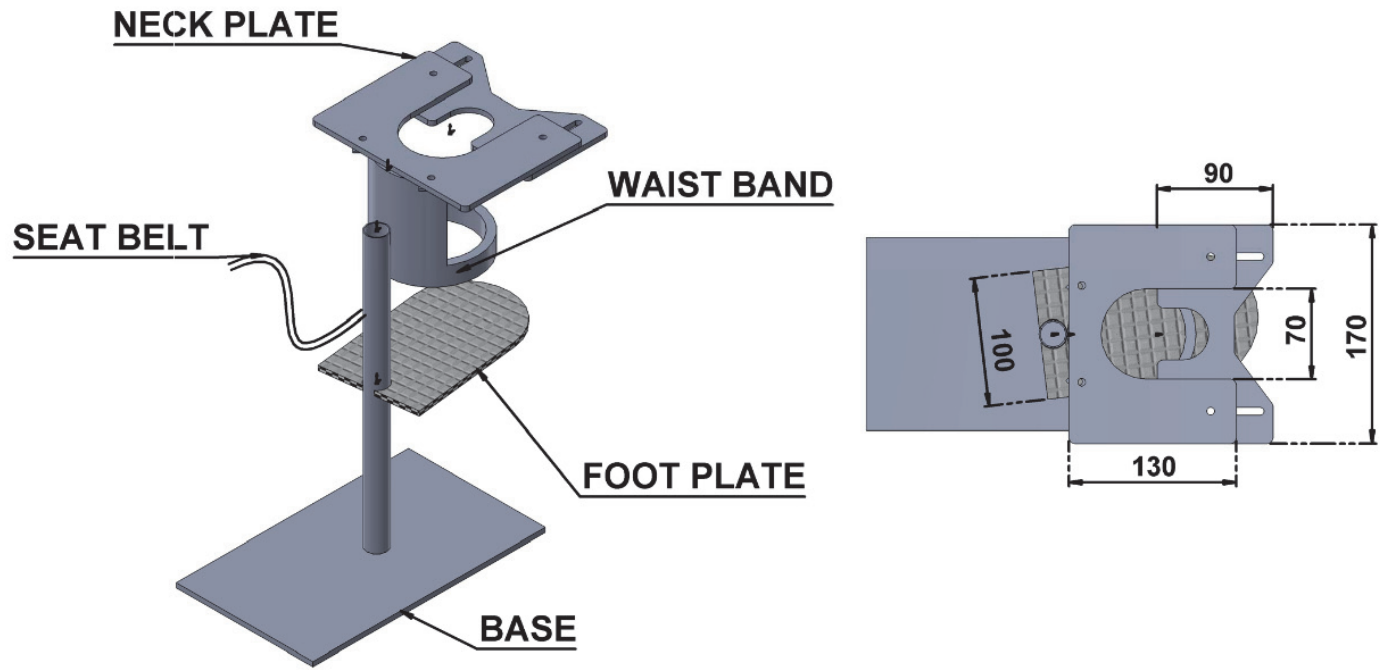

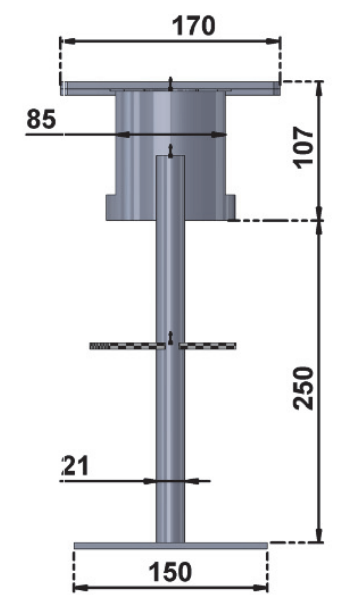

NOT TO SCALE

Figure 3: (A) Schematic of the Scoop for handling the monkeys. (B) Schematic of the Custom Made Marmoset Chair. Not to scale. Dimensions in mm. Attachment mechanisms (screws etc) not shown. 
(A)

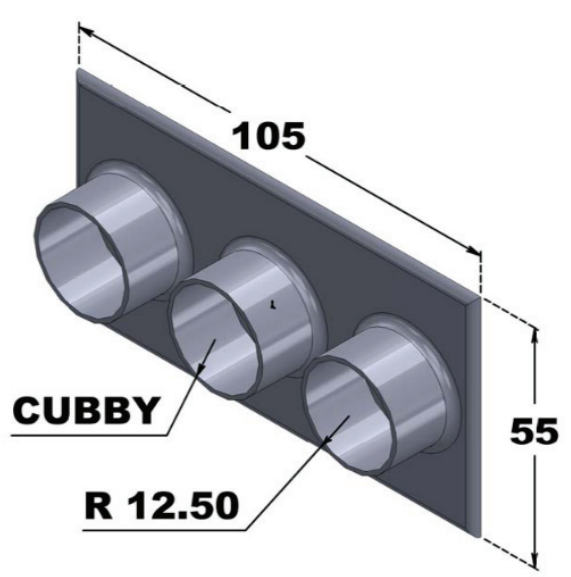

(B)
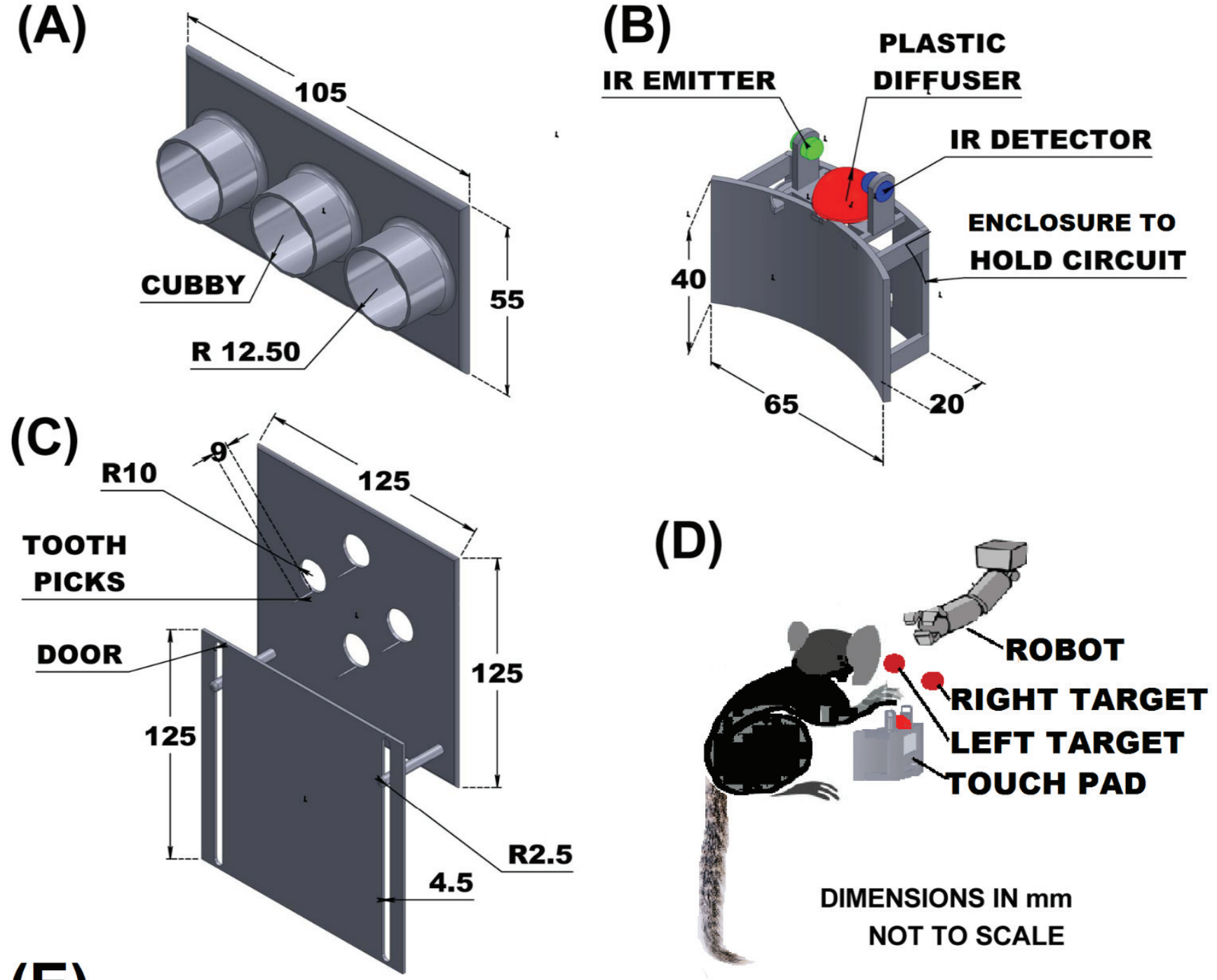

(E)
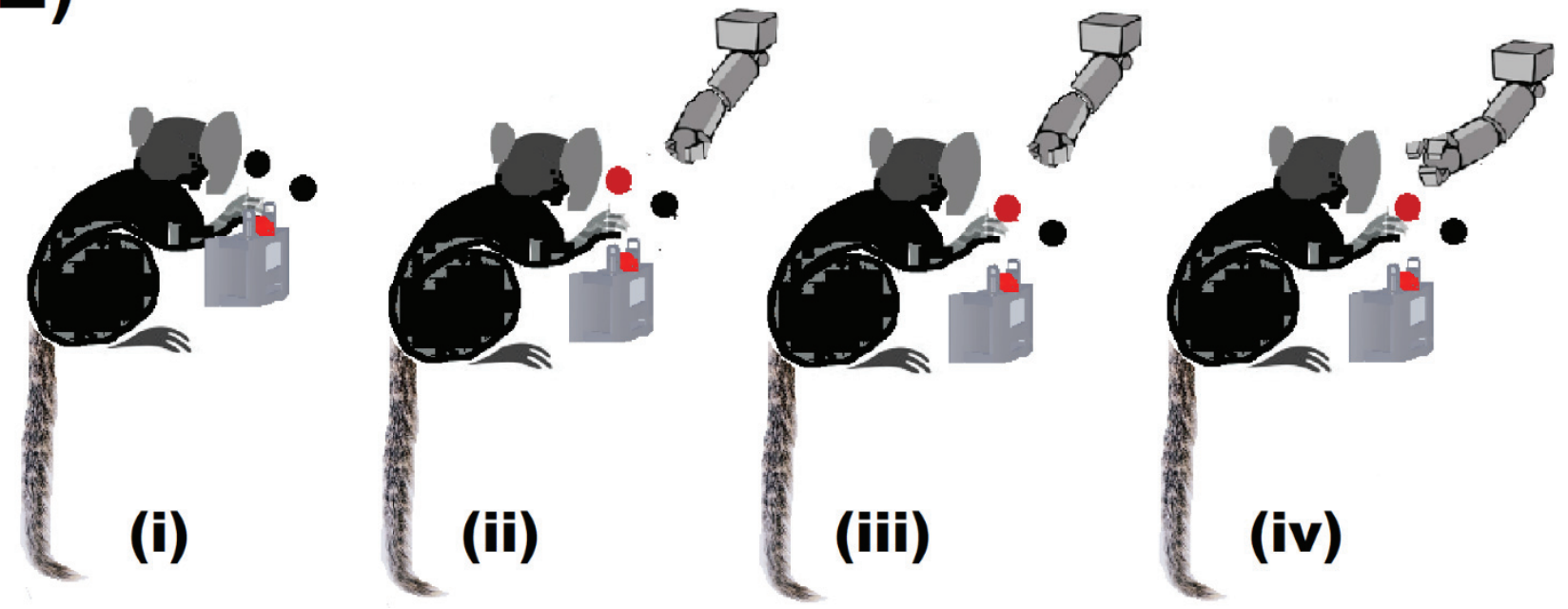

Figure 4: Devices for Training. (A) Cubby Hole device. (B) Touch Pad. (C) Door Device. (D) Robot Task. Not to scale. Dimensions in mm. Attachment mechanisms (screws etc) not shown. (E) 2-target Robot task. (i) animal keeps hand in touch pad to initiate the trial. (ii) once the trial is initiated, one of the targets (left) lights up and the robot comes out holding a treat. (iii) animal reaches and triggers the left target. (iv) robot moves to the left and the animal gets a reward. 


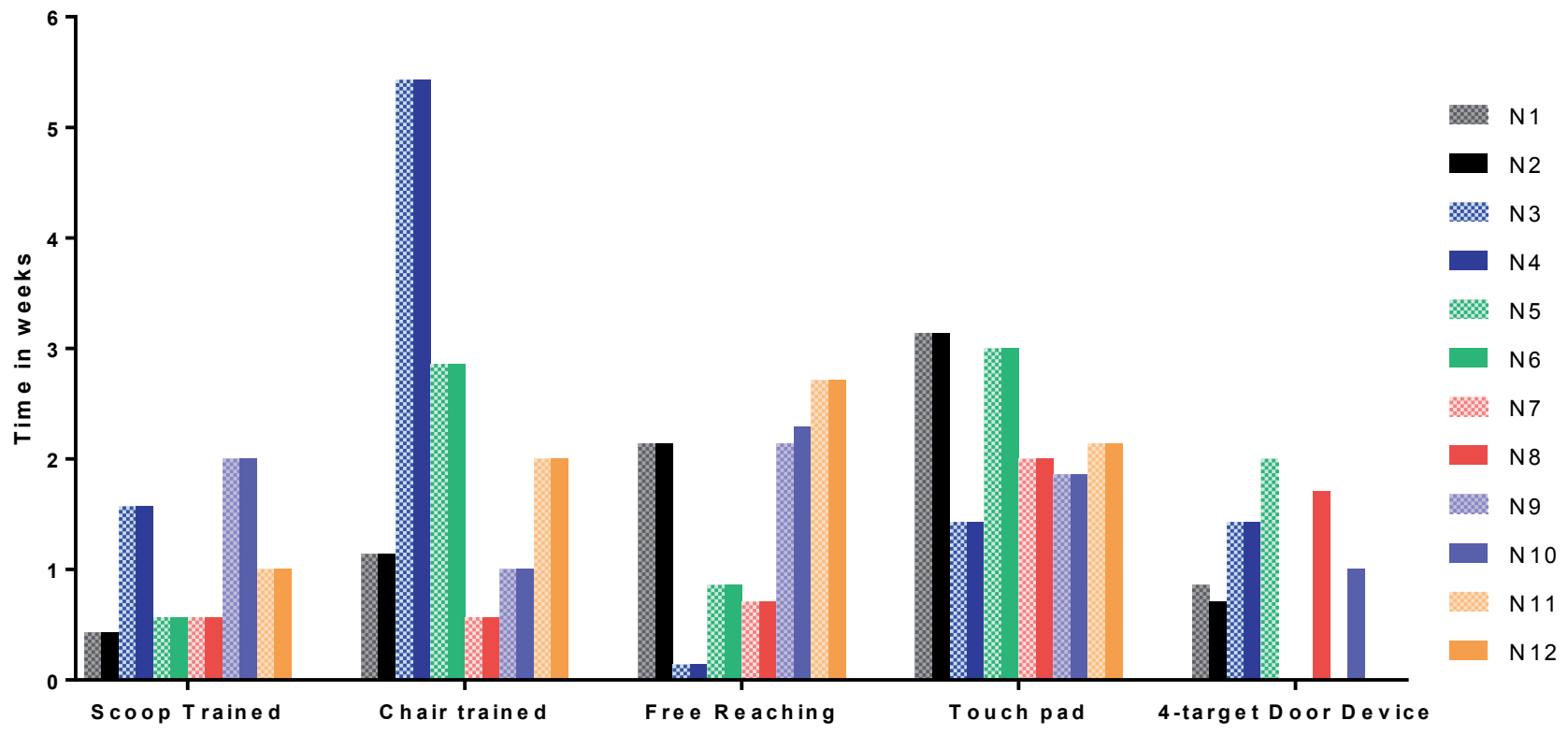

Figure 5: Training Times for different animals on different tasks in weeks. Monkeys trained in pairs are shown in same color, lighter and darker. 
(A)

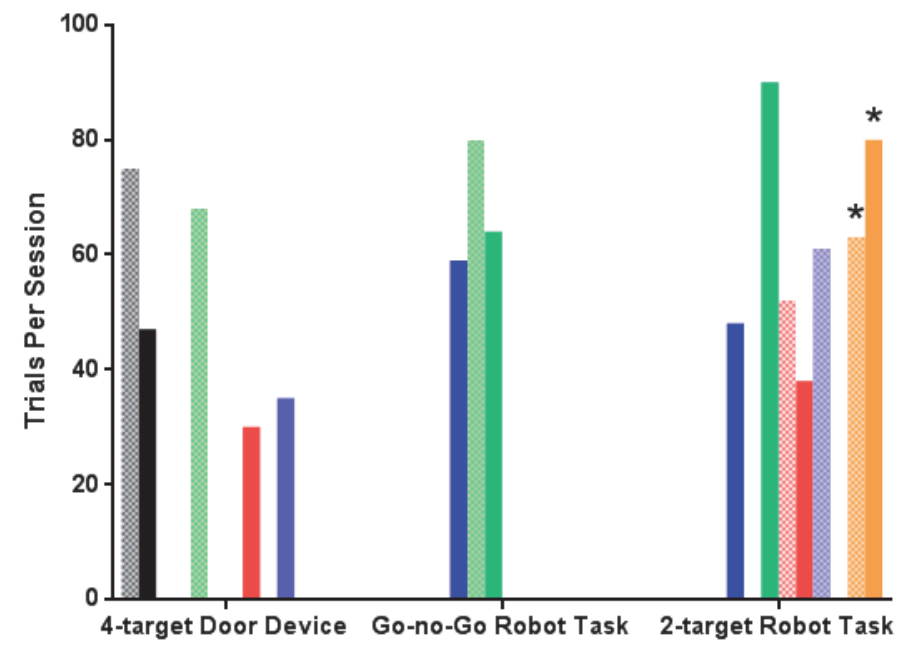

(B)

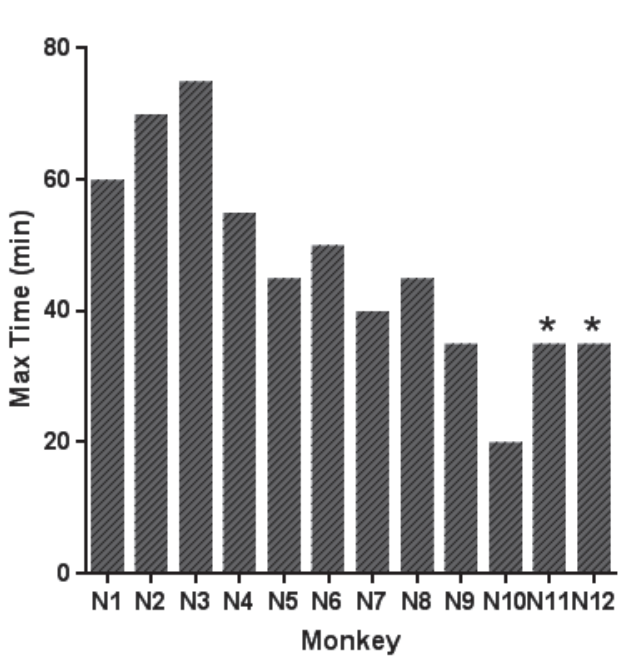

Figure 6: (A) Trails per session when fully trained and (B) Length of time per session for each animal. *Animals N11 and N12 are being trained at present and the values shown are the present values. 

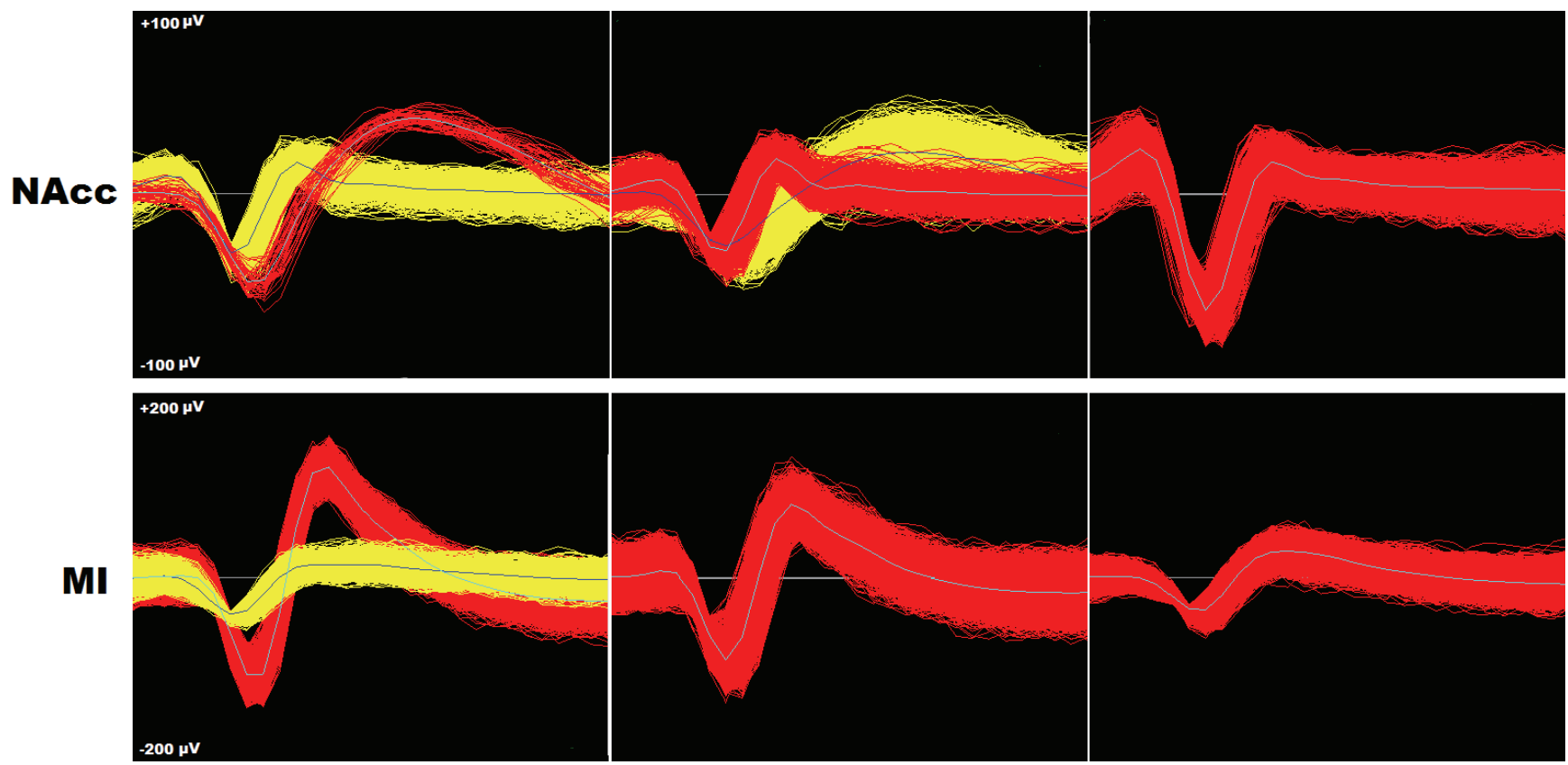

Figure 7: NAcc and MI recordings from 3 electrodes each (spike sorted manually) from animal N4, 2 months after implant 


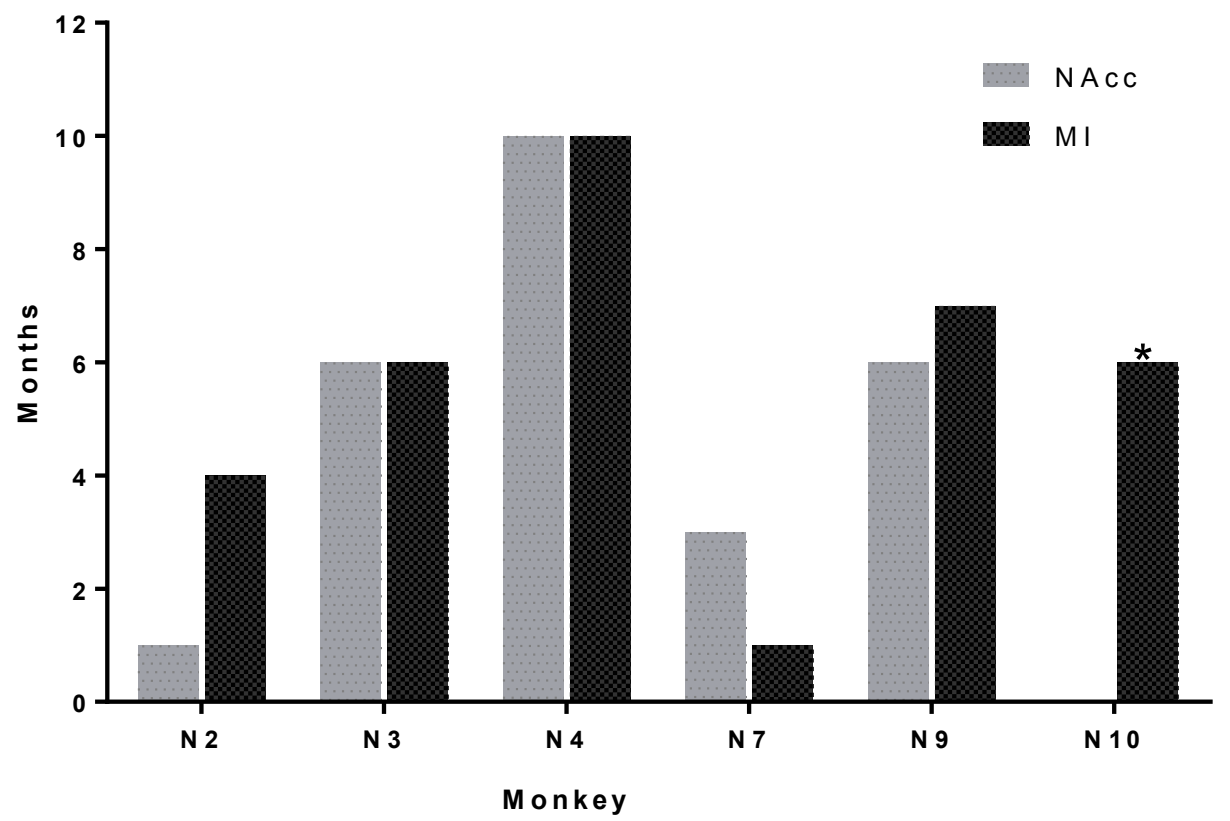

Figure 8: NAcc and MI longevity (in months) of the recordings for 6 monkeys. *Animal N10: the array is still intact and is being recorded from (6 months so far). 